\title{
Micro TJE centrifugal compressor performance prediction
}

\section{Original Article}

\author{
Tamer S. Fathy ${ }^{1}$, Aly M. Elzahaby ${ }^{2}$, and Mohamed K. Khalil ${ }^{3}$ \\ ${ }^{1}$ Egyptian Armor Department, Ministry of Defence, ${ }^{2}$ Department of Mechanical \\ Engineering, Faculty of Engineering, Tanta University, Tanta, Egypt, ${ }^{3}$ Military \\ Technical College, Cairo, Egypt
}

\section{Keywords:}

ANSYS CFX, Centrifugal compressor characteristic, off-design performance, MATLAB, Micro turbojet

\section{Corresponding Author:}

Tamer S. Fathy, Military Technical College, Ministry of Defence, Tel: 01019971921

Email: tamer_vivi01@icloud.com

\section{Abstract}

In this paper, the performance of a small centrifugal compressor of an UAV at design and off-design operational conditions is estimated by way of advanced commercial CFD code, ANSYS-CFX-16. Then, the gained performance is compared with published predicted performance using approximate method ${ }^{[1,2]}$. The engine used is JetCat P200-sx, which is a single spool turbojet. Considered off-design regimes include centrifugal compressor operations at $73 \%, 80 \%, 85 \%, 90 \%, 100 \%$ and $103 \%$ of the design point rotational speed. Commercial CFD code CFX-16, is used for compressor performance prediction at design and off- design operating conditions. The computational grid is created using Turbo-Grid for compressor parts impeller and vanned diffuser. While for both intake device and vaneless diffuser an unstructured tetrahedral mesh with prism layers along the wall surfaces using ANSYS-ICEM CFD mesh is used to resolve the near-wall boundary layer. To gain a reduction in the computational analysis cost, only one passage is considered as a portion of the computational domain and the model is simulated as a steady state problem. Finally, to detect the surge point at each rotational speed the unsteady simulation on performance predictions of centrifugal compressor is investigated. It is a common practice to use compressor characteristics available in graphical form. These plots can be transformed into empirical equations that can be used in automatic calculation. Such approach was done to predict the same compressor performance ${ }^{[13]}$. The CFD detailed compressor performance is compared with the mentioned published one. The numerical CFD results illustrate good agreement with the analytical model.

\section{INTRODUCTION}

Nowadays it is really common to use centrifugal compressors in extensively way for industrial applications when there is a need for highly pressurized gas. The centrifugal compressor pressure ratio arrays from 1 to 1.3 per stage for those used in industrial processes, 3 to 7 for small GTE's and regularly 13 for centrifugal compressors used in the experimental replicas ${ }^{[3]}$. Small TJE's compressors and turbochargers are the most common examples.

Figure 1 shows components and station numbering of a small TJE. Amongst all examples of small TJEs, the small gas turbines have practiced a growing attention lately. These engines have great energy capacity compared to their total weight and consequently this makes these engines striking for use in small propulsion vehicles like UAVs, model airplanes and missiles ${ }^{[4]}$. 



Fig. 1: Components and station numbering within engine

The compressor operating performance is represented by a map demonstrating the relation between pressure ratio and air mass flow rate, $\dot{m}$. The serviceable segment of the map linked to centrifugal compressors is restricted by the surge line, the choke line and the maximum permitted compressor speed.

The surge line gives the limitation of the map on the left side. This characterizes the limitation of the air mass flow at the inlet of the compressor. If the pressure ratio becomes too high and the volume flow becomes too small, the air no longer sticks to the blades suction side which leads to an interruption in the discharge process. The air flow stops from going through the compressor and is overturned until reaching the state of stabilized pressure and the positive flow rate is successfully reached again, then the pressure builds up again and the cycle is repeated. The instability in flow creates surging which appears as pressure pulsation and noise.

The compressor inlet cross-section is typically the limitation of the maximum centrifugal compressor flow rate. If the flow at the inlet reaches its maximum velocity then the flow rate can no longer be increased. The choke line can be defined as the rapidly descending line on the right side of compressor's map. A typical map is shown in figure 2 .

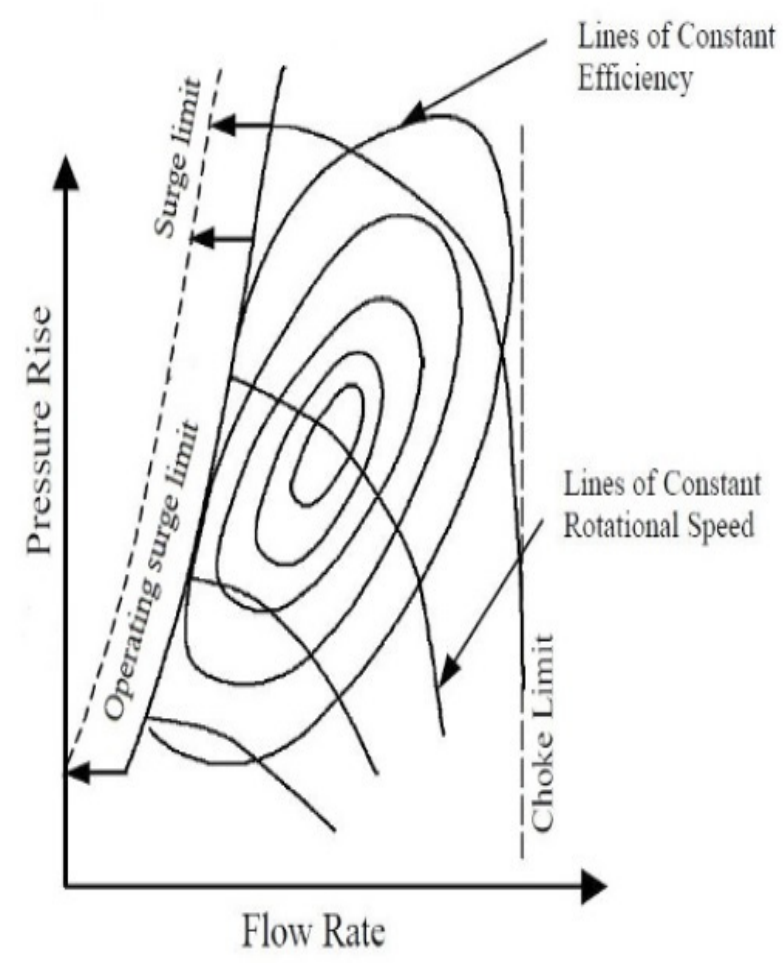

Fig. 2: A typical Centrifugal Compressor Map 
The complete technical specifications of JetCat P200-sx which is the selected micro TJE for this study are given in Table $1^{[5]}$. The JetCat P200-sx consists of a standard inlet (intake device), centrifugal compressor of a single stage with vane diffusers, an annular combustor, a single stage axial turbine and a convergent nozzle with speed range from 33,000 to $112,000 \mathrm{rpm}$. The impeller is composed of 6 main blades and 6 splitters (secondary blades) to reduce the blockage of the passing flow and the vanned diffuser contains 17 radial blades and 34 axial vanes.

Table 1: JetCat P200-sx technical specifications as provided from manufacture

\begin{tabular}{lc}
\hline Compressor pressure ratio, $\pi_{-}$ct & 3.7 \\
\hline $\mathrm{F}$ (idle) & $9 \mathrm{~N}$ \\
$\mathrm{~F}$ (maximum) & $230 \mathrm{~N}$ \\
$\mathrm{n}$ (idle) & $33000 \mathrm{rpm}$ \\
$\mathrm{n}$ (maximum) & $112000 \mathrm{rpm}$ \\
EGT(maximum) & $750^{\circ} \mathrm{C}$ \\
$\dot{m}$ & $0.45 \mathrm{~kg} / \mathrm{s}$ \\
Exhaust velocity(maximum) & $1840 \mathrm{~km} / \mathrm{h}$ \\
Fuel consumption(maximum) & $0.584 \mathrm{~kg} / \mathrm{min}$ \\
Fuel mixture (By volume) & $95 \%$ Jet-A $1+5 \% \mathrm{Mobil} \mathrm{jet} \mathrm{oil} 254$ \\
\hline
\end{tabular}

Previous studies were conducted on several micro TJEs' models, to predict their performance theoretically using CFD and / or analytical models ${ }^{[6-10]}$. Some of these studies used map scaling to expect the compressor performance variation at different rotational speeds ${ }^{[6-8]}$. Additional studies used CFD analysis and commercial software to predict it ${ }^{[9}$ and 10].

This paper is directed on studying the performance of micro TJEs by predicting it theoretically using commercial CFD code, ANSYS-CFX, and verifying this prediction using approximate method.

\section{Governing Equations}

In order to give a proper description of the flow behavior of centrifugal compressor it is important to discuss the mass and momentum conservation equations, the compression process is considered without heat exchange in simulation. CFD programs permit the user to split the model into separate parts named sub-domains, each one can have characteristics that are different from the other sub- domains. In this case of study, it is essential to divide the model into 4 different parts (intake device, impeller, vaneless diffuser and vanned diffuser). Three of these parts are fixed (stationary) while the sub-domain allocated to the impeller has an angular velocity. Consequently, for the same numerical simulation two different types of domains are synchronized, in order to connect these different subdomains (parts). ANSYS-CFX-16 offers the interfaces needed to deliver the data among different parts (domains). Each sub-domain has its individual mesh ${ }^{[11]}$.
To define the impeller rotational movement, it is required to assign the orientation framework of the model, where $\mathrm{Z}$ axis is considered as the rotational axis. And the domain specified to the impeller (rotor) is confirmed that it shares the same rotational axis and passes through the original $(0,0,0)$ point of the orientation framework. Additional relations must be involved on the momentum equations to designate the flow on this domain accurately.

Numerical simulations are classified into three different groups: RANS (Reynolds Averaged Navier-Stokes), LES (Large Eddy Simulation) and DNS (Direct numerical simulations). The work in this paper can be considered as a RANS simulation, which is most common suitable for the treated problem using CFD's. The LES upon which the flux equations that are time dependent are to be solved for the biggest turbulences and in the same time modeling the effect of the smaller swirling flow. The DNS model for the mean time is only appropriate for microscopic scales, it solves entirely the Navier-Stokes equations, however it needs high capability solver.

In this paper, taking the assumption of Reynolds average equations and Boussinesq hypothesis a turbulence flow managed by the mass and momentum conservation equations is used. With this supposition on turbulence modeling and considering non-inertial reference framework system $(\mathrm{x}, \mathrm{y}, \mathrm{z})$, the equations of conservation of mass (2.1) and momentum (2.2), (2.3) and (2.4) are described as follows:

$$
\frac{\partial \bar{u}}{\partial x}+\frac{\partial \bar{v}}{\partial y}+\frac{\partial \bar{w}}{\partial z}=0
$$




$$
\begin{aligned}
\frac{\partial \bar{u}}{\partial t}+\frac{\partial \overline{u u}}{\partial x}+\frac{\partial \overline{u v}}{\partial y}+ & \frac{\partial \overline{u w}}{\partial z} \\
& =-\frac{1}{\rho} \frac{\partial \bar{p}}{\partial x}+\frac{\partial}{\partial x}\left[\left(v+v_{t}\right)\left(2 \frac{\partial \bar{u}}{\partial x}\right)\right]+\frac{\partial}{\partial y}\left[\left(v+v_{t}\right)\left(\frac{\partial \bar{u}}{\partial y}+\frac{\partial \bar{v}}{\partial x}\right)\right] \\
& +\frac{\partial}{\partial z}\left[\left(v+v_{t}\right)\left(\frac{\partial \bar{u}}{\partial z}+\frac{\partial \bar{w}}{\partial x}\right)\right]+D_{x}
\end{aligned}
$$

$$
\begin{aligned}
\frac{\partial \bar{v}}{\partial t}+\frac{\partial \overline{v u}}{\partial x}+\frac{\partial \overline{v v}}{\partial y}+\frac{\partial \overline{v w}}{\partial z} & \\
= & -\frac{1}{\rho} \frac{\partial \bar{p}}{\partial y}+\frac{\partial}{\partial y}\left[\left(v+v_{t}\right)\left(2 \frac{\partial \bar{v}}{\partial y}\right)\right]+\frac{\partial}{\partial x}\left[\left(v+v_{t}\right)\left(\frac{\partial \bar{u}}{\partial y}+\frac{\partial \bar{v}}{\partial x}\right)\right] \\
& +\frac{\partial}{\partial z}\left[\left(v+v_{t}\right)\left(\frac{\partial \bar{v}}{\partial z}+\frac{\partial \bar{w}}{\partial y}\right)\right]+D_{y}
\end{aligned}
$$

$$
\begin{aligned}
\frac{\partial \bar{w}}{\partial t}+\frac{\partial \overline{w u}}{\partial x}+ & \frac{\partial \overline{w v}}{\partial y}+\frac{\partial \overline{w w}}{\partial z} \\
& =-\frac{1}{\rho} \frac{\partial \bar{p}}{\partial y}+\frac{\partial}{\partial y}\left[\left(v+v_{t}\right)\left(2 \frac{\partial \bar{w}}{\partial z}\right)\right]+\frac{\partial}{\partial x}\left[\left(v+v_{t}\right)\left(\frac{\partial \bar{w}}{\partial x}+\frac{\partial \bar{u}}{\partial z}\right)\right] \\
& +\frac{\partial}{\partial y}\left[\left(v+v_{t}\right)\left(\frac{\partial \bar{w}}{\partial y}+\frac{\partial \bar{v}}{\partial z}\right)\right]
\end{aligned}
$$

If rotation presets for the domain, then the angular velocity must be included ; in this case, the terms $D_{x}$ and $D_{v}$ and are described in equations (2.5) and (2.6):

$$
\begin{aligned}
& D_{x}=-2 \omega_{z} \bar{v}-\omega_{z}^{2} x \\
& D_{y}=-2 \omega_{z} \bar{u}-\omega_{z}^{2} y
\end{aligned}
$$

For static domains, these terms $D_{x}$ and $D_{y}$ are zero. The turbulent kinetic viscosity is defined in the following equation:

$$
v_{t}=\frac{\mu_{t}}{\rho}
$$

Two equations turbulent model $k-\varepsilon$ is used in this case of study; in this model a mathematical relation bonding between $v_{t}$ with both $k$ and $\varepsilon$ and is presented in equation (2.8):

$$
v_{t}=\frac{h_{\mu} k^{2}}{\varepsilon}
$$

Where:

$k:$ turbulent kinetic energy

$\varepsilon:$ energy diffusion ratio

$h_{\mu}$ : constant for the $k-\varepsilon$ turbulent model.

The equation defining both $k$ and $\varepsilon$, respectively, are shown in equations (2.9) and (2.10):

$$
\begin{aligned}
& \frac{\partial k}{\partial t}+\frac{\partial u k}{\partial x}+\frac{\partial v k}{\partial y}+\frac{\partial w k}{\partial z}=S_{k}+P_{k}-k \\
& \frac{\partial \varepsilon}{\partial t}+\frac{\partial u \varepsilon}{\partial x}+\frac{\partial v \varepsilon}{\partial y}+\frac{\partial w \varepsilon}{\partial z}=S_{z}+\frac{\varepsilon}{k}\left(h_{t 1} P_{k}-h_{z 2} \varepsilon\right)
\end{aligned}
$$

Where:

$S_{k}$ and $S_{\varepsilon}$ : diffusive terms for $k$ and $\varepsilon$

$P_{k} \quad:$ define the production of $k$, and

$h_{\varepsilon 1}, h_{\varepsilon 2}$ : coefficients from the $k-\varepsilon$ model

Explanation of $S_{k}, S_{\varepsilon}$ and $P_{k}$ are defined in equations (2.11), (2.12) and (2.13) 


$$
\begin{gathered}
S_{k}=\frac{\partial}{\partial x}\left[\left(v+\frac{v_{t}}{\sigma_{k}}\right) \frac{\partial k}{\partial x}\right]+\frac{\partial}{\partial y}\left[\left(v+\frac{v_{t}}{\sigma_{k}}\right) \frac{\partial k}{\partial y}\right]+\frac{\partial}{\partial z}\left[\left(v+\frac{v_{t}}{\sigma_{k}}\right) \frac{\partial k}{\partial z}\right] \\
S_{\varepsilon}=\frac{\partial}{\partial x}\left[\left(v+\frac{v_{t}}{\sigma_{\varepsilon}}\right) \frac{\partial \varepsilon}{\partial x}\right]+\frac{\partial}{\partial y}\left[\left(v+\frac{v_{t}}{\sigma_{\varepsilon}}\right) \frac{\partial \varepsilon}{\partial y}\right]+\frac{\partial}{\partial z}\left[\left(v+\frac{v_{t}}{\sigma_{\varepsilon}}\right) \frac{\partial \varepsilon}{\partial z}\right] \\
P_{k}=v_{t}\left\{\left(\frac{\partial \bar{u}}{\partial y}+\frac{\partial \bar{v}}{\partial x}\right)^{2}+\left(\frac{\partial \bar{u}}{\partial z}+\frac{\partial \bar{w}}{\partial x}\right)^{2}+\left(\frac{\partial \bar{v}}{\partial z}+\frac{\partial \bar{w}}{\partial y}\right)^{2}\right. \\
\left.+2\left[\left(\frac{\partial \bar{u}}{\partial x}\right)^{2}+\left(\frac{\partial \bar{v}}{\partial y}\right)^{2}+\left(\frac{\partial \bar{w}}{\partial z}\right)^{2}\right]\right\}
\end{gathered}
$$

Where $: \sigma_{k}$ and $\sigma_{\varepsilon}$ are the Pradnt number for $k$ and $\varepsilon$,

the values of the coefficients of $k-\varepsilon$ are:

$h_{\mu}=0.09, \sigma_{k}=1.00, \sigma_{\varepsilon}=1.30, h_{\varepsilon 1}=1.44, h_{\varepsilon 2}=1.92^{[12]}$.

\section{Domain Interfaces}

Using ANSYS-CFXfor the centrifugal compressor study case, two different kinds of interfaces can be defined. Interfaces can be used to connectstatic meshes or to connect a static mesh with a rotational one. Table. 2 shows the two kinds of interfaces.

Table 2: ANSYS-CFX Interfaces

\begin{tabular}{lcc}
\hline Simulation Type & Interface model available between static meshes & $\begin{array}{c}\text { Interface models available between } \\
\text { stationary and rotational meshes }\end{array}$ \\
\hline
\end{tabular}

$\begin{array}{lll}\text { Steady State } & \text { GGI } & \text { Stage, Frozen Rotor }\end{array}$

GGI type connection is the simplest of all types of connections, because of that the frame in this situation is static combined with an always constant relative position between cells.

In Steady State simulation with the aim of combine a static mesh with a rotational one, a choice between Stage or Frozen rotor can be taken. Knowing that for these two interfaces models the relative movement between their meshes is not designated, internally calculations of thedegrees rotated by the rotor (impeller) is done by ANSYS-CFX and that data is linked every time step. Receivingthe data of two adjacent time steps and post process the situation of the meshes are combined with the intention of the relative position remains to be the same.

Frozen rotor method differs from the stage (mixing plane) method as named in CFX in dealing with flow in the interface for both upstream and downstream components. The stage mixes the flow and use the average quantities on the interface for the upstream and downstream components. Though frozen rotor passes the true flow to downstream and vice versa. So, if it is interested in the wake effect on the performance of downstream component then frozen rotor method is selected. The disadvantage of frozen rotor method is that, it gives the solution at the single relative position. Thus, if it is essential to get the wake effect on downstream component for all relative positions, which does happen in reality, then the true transient method should be considered.

If the main direction of the passing flow is parallel to the normal vector of the cell's face (perpendicular to the face) then the Stage interface is appropriate. The Frozen Rotor interface is appropriate when the direction of the passing flow is perpendicular to the normal vector (has a relatively high tangential component trough the interface surface).

The last kind of interfaces is called Transient Rotor Stator which only available for transient simulations. This model is the only one capable of reporting the whole relative movement between meshes as it gives more precise results but in the other hand needs more processing time.

In this case of study, four interfaces are defined for the compressor model, the first interface is between the intake device and the impeller sub domain, the second one connects the impeller and the vaneless diffuser, the third one connects the vaneless diffuser with the radial blade of the vanned diffuser and the last one is placed between 
the radial part of diffuser and the exit sub-domain which contains the axial part of diffuser, see details on figure 3 .

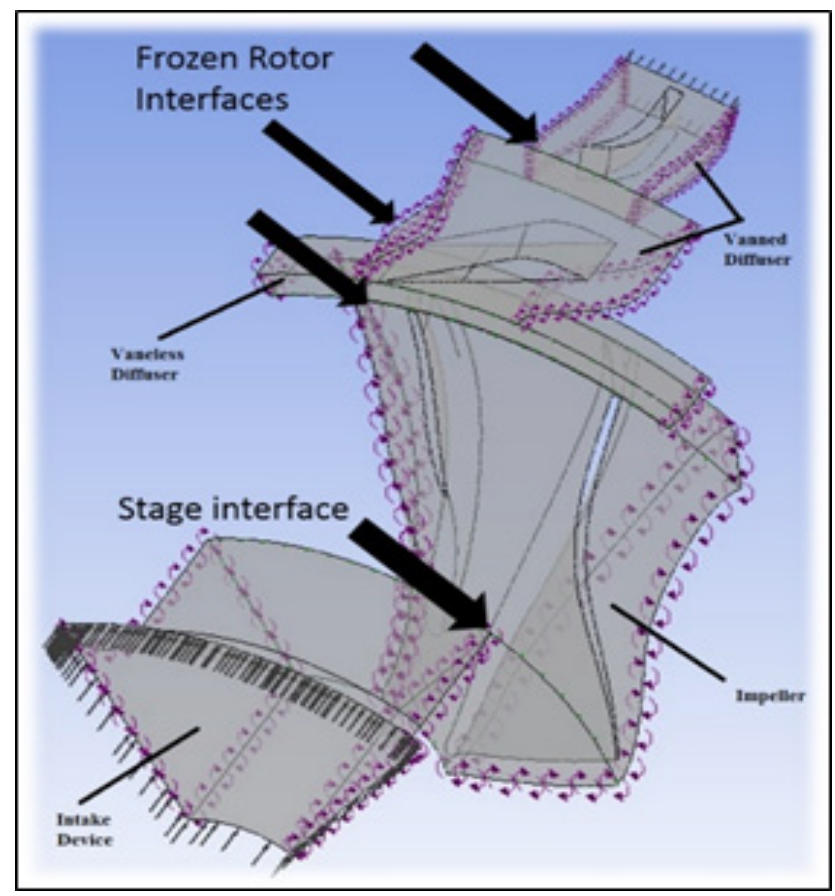

Fig. 3: Domain Interfaces in JetCat's Compressor

\section{Numerical Solution Technique 4.1. Geometry Preparation}

A reverse engineering methodology isusedin order to attain a full 3-Dimensional geometry of the JetCat P200sx centrifugal compressor. Initially the TJEis carefully disassembled until the centrifugal compressor is visibly realized. At that time a CMMis used to separately measure point coordinates on the centrifugal compressor components (impeller, vaneless diffuser, vanned diffuser and elbow).

Because of the small size of the impeller features relative to the scanning sensorit was so hard to obtain a precise measurement of the impeller, for several times the sensor had to be re-orientated to allow it to reach all areas of the impeller while avoiding contact between the impeller and other parts of the CMM.

The CMM used for scanning is a ZEISS MICURA CMM which offers active scanning withmeasuring accuracy of less than one micrometer. Because of the small size of the impellerfeatures relative to the scanning sensor it was so hard to obtain a precise measurement of theimpeller. For several times the sensor had to be re-orientated to allow it to reach all areas of theimpeller whileavoiding contact between the impeller and other parts of the CMM.

To solve this problem an optical laser scanner is used $^{[14]}$ for the impeller blades and splitters. The optical scanner has a much less bulky tool compared to the CMM. The resulting point cloud is processed on Siemens NX9 software to deal with the parameterized model of the compressor parts. Figure 4 shows optical scanner on impeller during the scanning procedure and also shows the resulting point cloud from the scan.

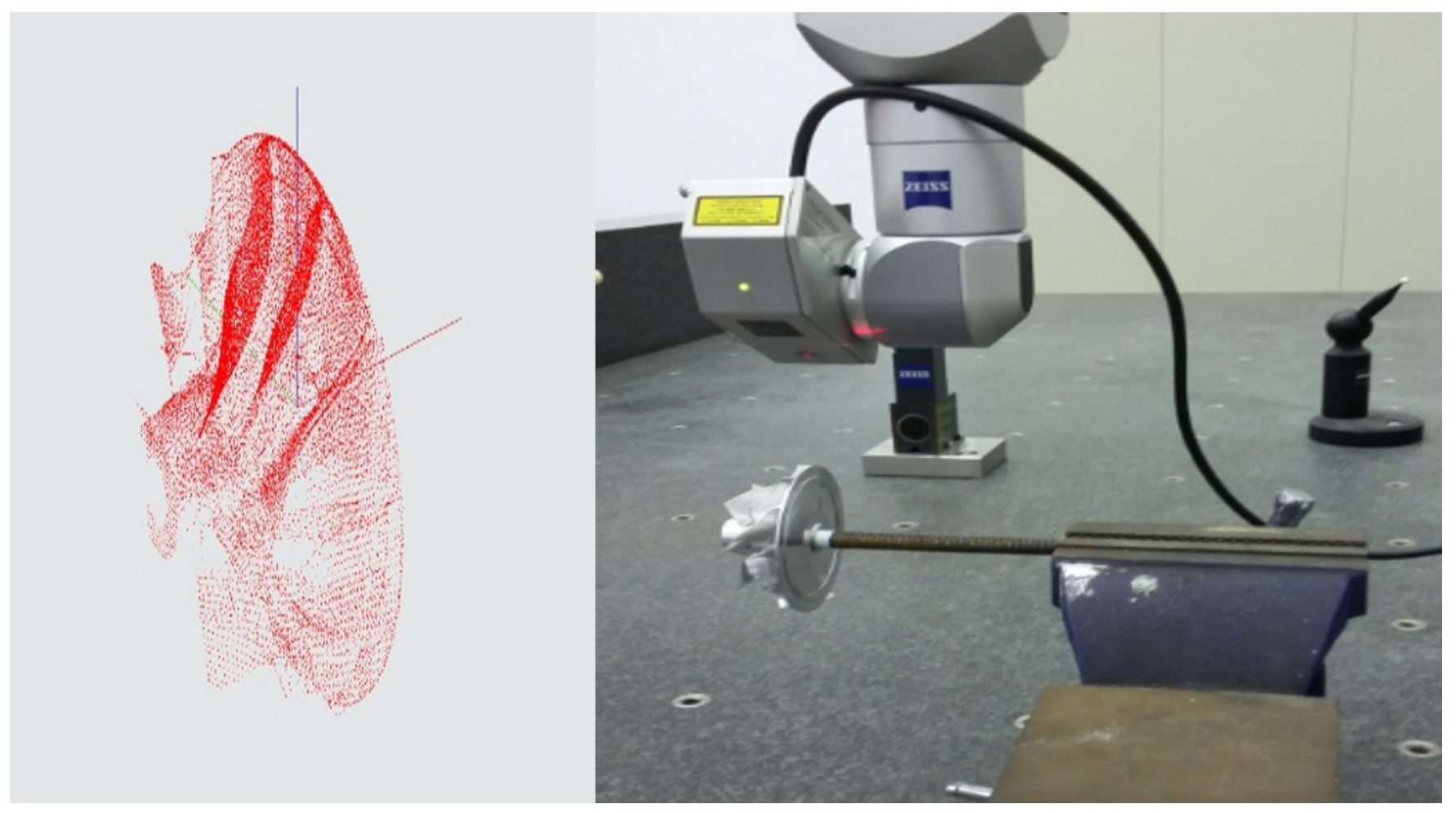

Fig. 4: Optical laser scanning of impeller ${ }^{[14]}$ 
Because of periodicity structural features of the geometry of impeller, only single channel (passage) holding only one main blade and one splitter is modelled. To guarantee a good transition between the impeller and the diffuser and to decrease the computation costs. The same periodicity on geometry of diffuser is applied. The mesh of the model is created with ANSYS TurboGrid ${ }^{[11]}$, which automates the creation of high quality hexahedral meshes desired for blade passages in the rotating impeller and the diffuser, as seen in figures 5,6 and 7 .

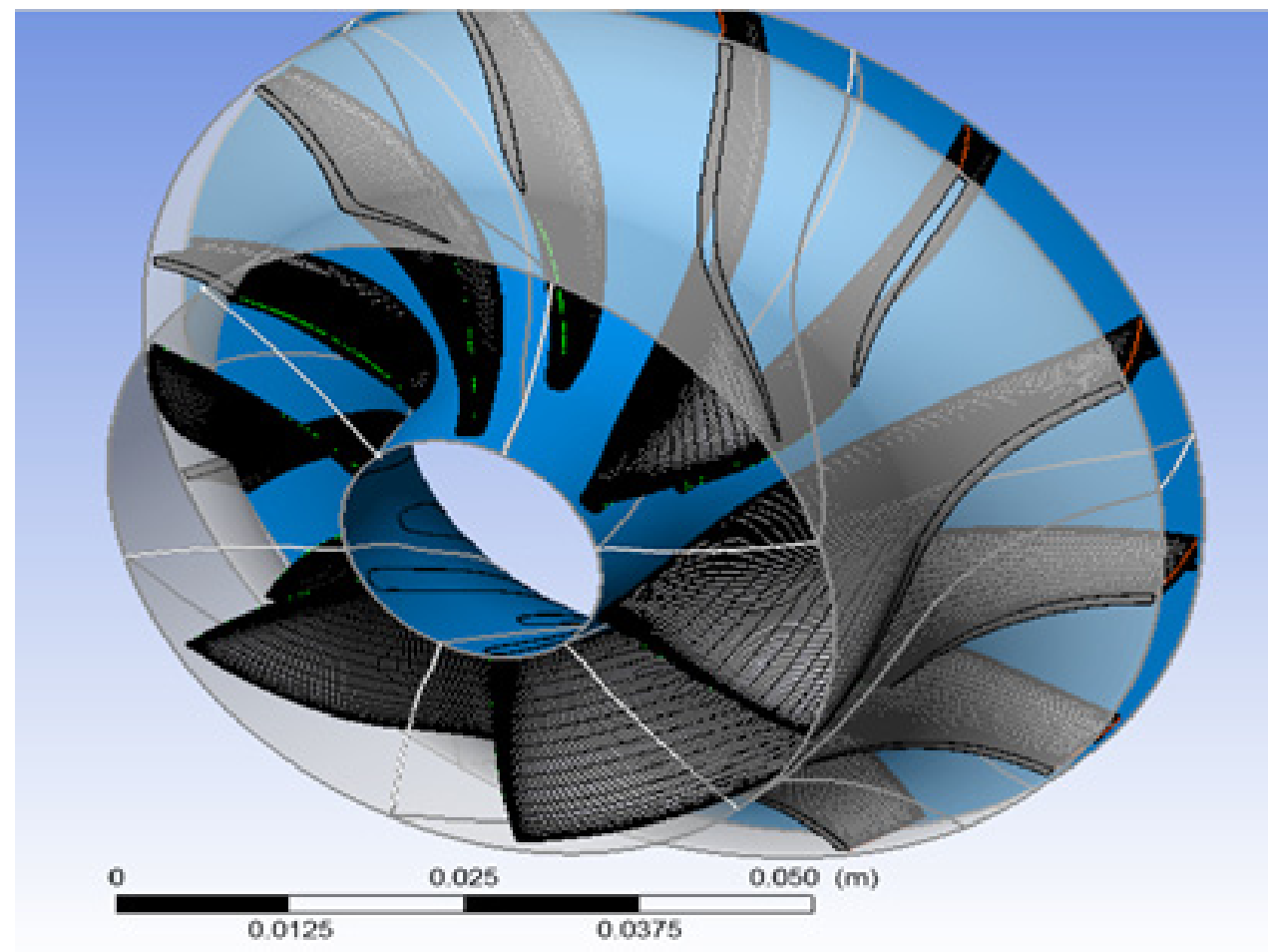

Fig. 5: Meshing of impeller using ANSYS TurboGrid
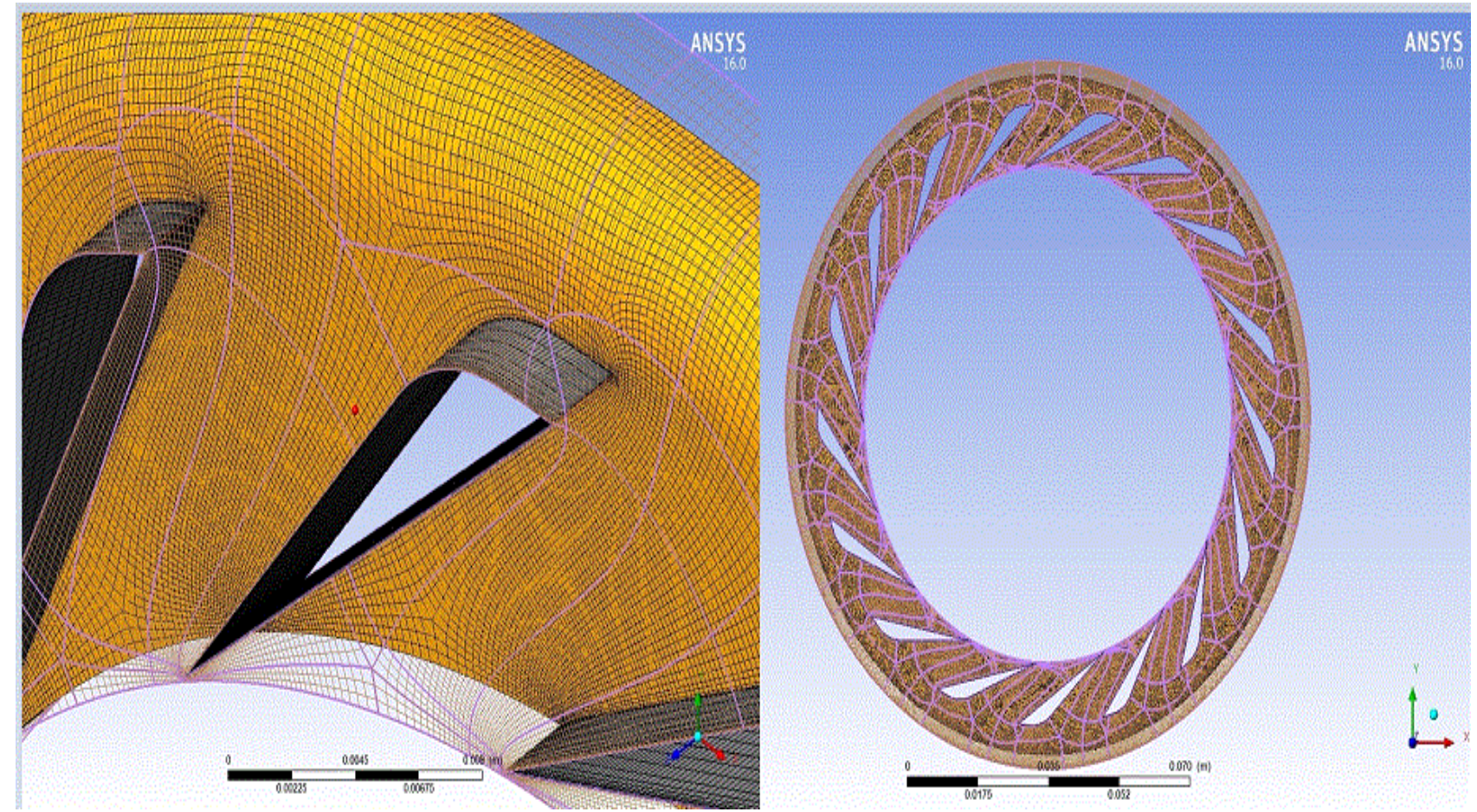

Fig. 6: Meshing of radial part of vanned diffuser using ANSYS TurboGrid 


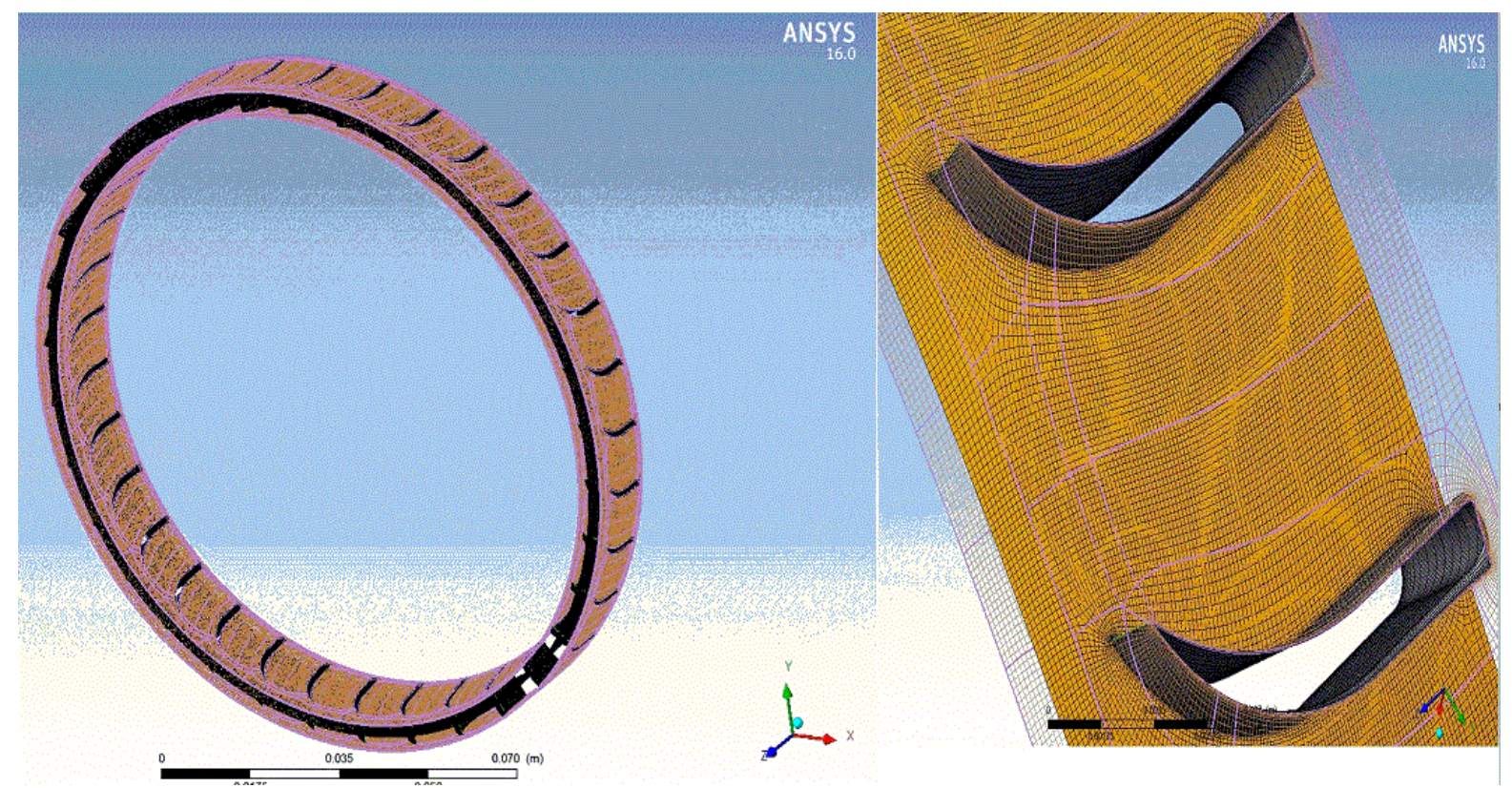

Fig. 7: Meshing of Axial part of Vanned Diffuser using ANSYS TurboGrid

An unstructured mesh is used for the simulation of both the intake and vaneless diffuser using ANSYS-ICEM CFD-Mesh ${ }^{[1]}$. As in figure 8.

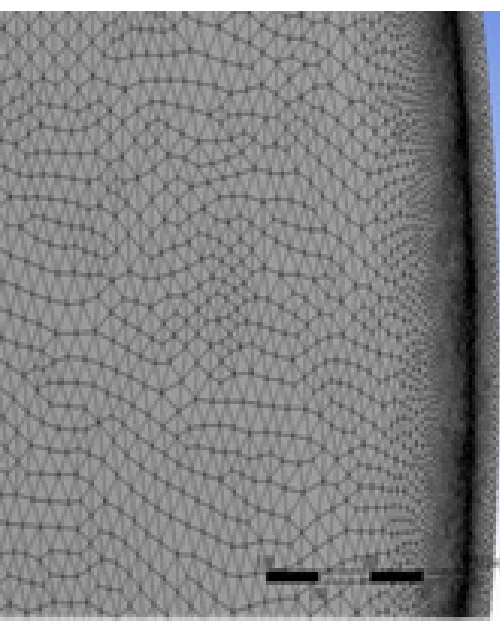

a-Intake
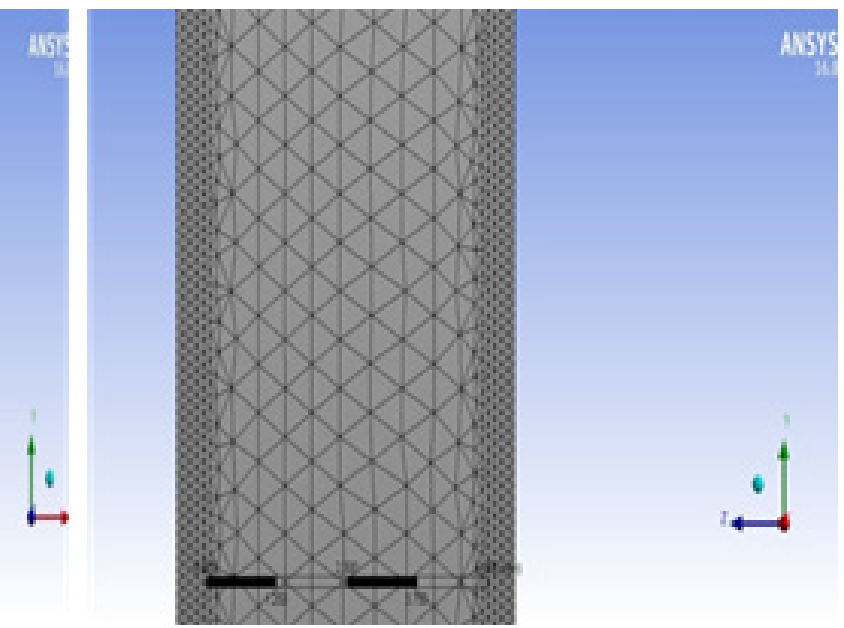

b- Van eless diffuser

Fig. 8: Meshing of intake and Vaneless Diffuser using ANSYS-ICEM CFD Mesh

\subsection{Grid independence test}

Precision of results hang on grid resolution. Grid refining can be continued up to a certain limit known as grid independence limit (GIL) at which the obtained results does not have significant change. The total pressure at the compressor outlet at design speed is taken to evaluate the grid independence test of the computational domain. Various level of grid refinement used for grid independence test are shown in Table. 3. The total pressure at compressor outlet with respect to the grid refinement level is shown in Figure 9. The results illustrate that there are deviations in the computed value of the total pressure at compressor outlet for the grid refinement level from 1 to 5 and also shows that the grid refinement level 6 has an acceptable value of deviation compared with level 7. So, grid refinement level 6 is selected. The refinement level consists of 1160486 nodes and 2004247 elements for final simulation of the computational domain. 
Table 3: Mesh refinement levels

\begin{tabular}{lcccc}
\hline Grid refinement level & Total number of nodes & Total number of elements & $\begin{array}{c}\text { The total pressure at } \\
\text { compressor outlet [Pa] }\end{array}$ & deviation \% \\
\hline 1 & 608538 & 1256401 & 235250 & - \\
2 & 662409 & 1313787 & 250660 & 6.55 \\
3 & 803837 & 1443973 & 326670 & 30.324 \\
4 & 865330 & 1503300 & 369540 & 13.123 \\
5 & 982350 & 1723500 & 379650 & 2.735 \\
7 & 1160486 & 2004247 & 379770 & 0.0315 \\
\hline
\end{tabular}

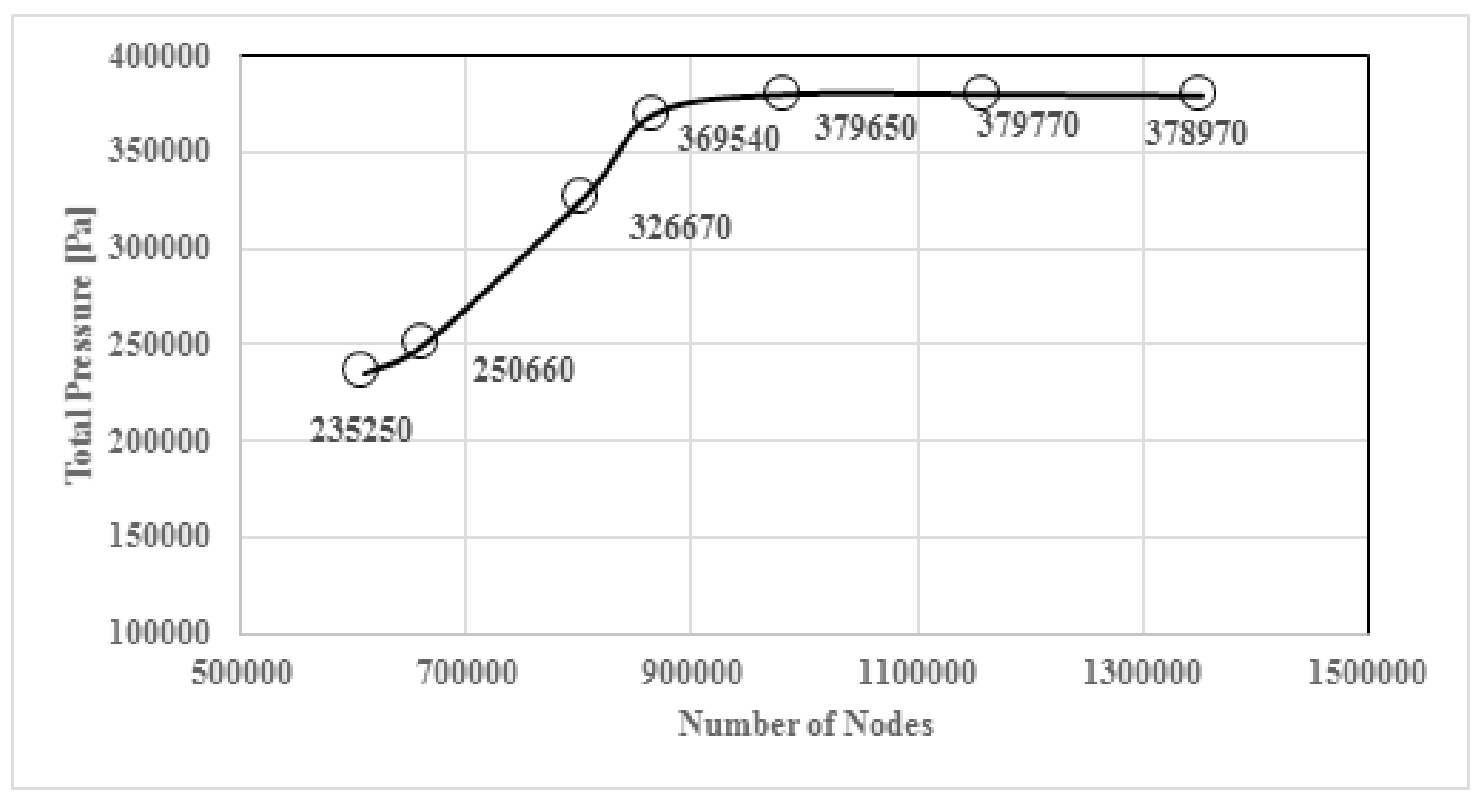

Fig. 9: Grid independence test of computational domain

In Table 4, the number of cells of each domain is specified which is determined by grid independency test for each domain.

Table 4: Mesh Statics

\begin{tabular}{lcc}
\hline Domain Name & Number of Nodes & $\begin{array}{c}\text { Number of } \\
\text { Elements }\end{array}$ \\
\hline Intake & 62775 & 336317 \\
Impeller & 418507 & 388764 \\
Vaneless Diffuser & 190084 & 1019014 \\
Radial Diffuser & 210656 & 194460 \\
Axial Diffuser & 278464 & 260152 \\
(Exit) & 1160486 & 2004247 \\
Total & & \\
\hline
\end{tabular}

\section{Boundary Conditions}

A single-phase flow turbulence simulation is used in this paper. The fluid is air as idle gas and the reference pressure of 0 Pascal as gauge pressure is selected. The following boundary conditions are selected. Thefluidisairasidlegasandthe reference pressure of 0 Pascal as gauge pressure is selected. The following boundary conditions are selected:

-Total pressure with a value of $101325 \mathrm{~Pa}$ at compressor inlet.

-Total temperature with a value of $288.15^{\circ} \mathrm{K} \mathrm{Pa}$ at compressorinlet.

-Static pressure at compressoroutlet.

$-5 \%$ turbulence intensity atinlet.

A constant physical time step with a value equals $1 \mathrm{E}-4$ is chosen and the mass flow rate $\mathrm{m}$ ' is evaluated at the centrifugal compressor outlet (exit).

The used CFD solves both steady and compressible Navier- Stokes equations, joined by $k-\varepsilon$ turbulence model.

Meridional plane of the JetCat P200-sx centrifugal compressor is shown in figure 10 using ANSYS-CFX. 


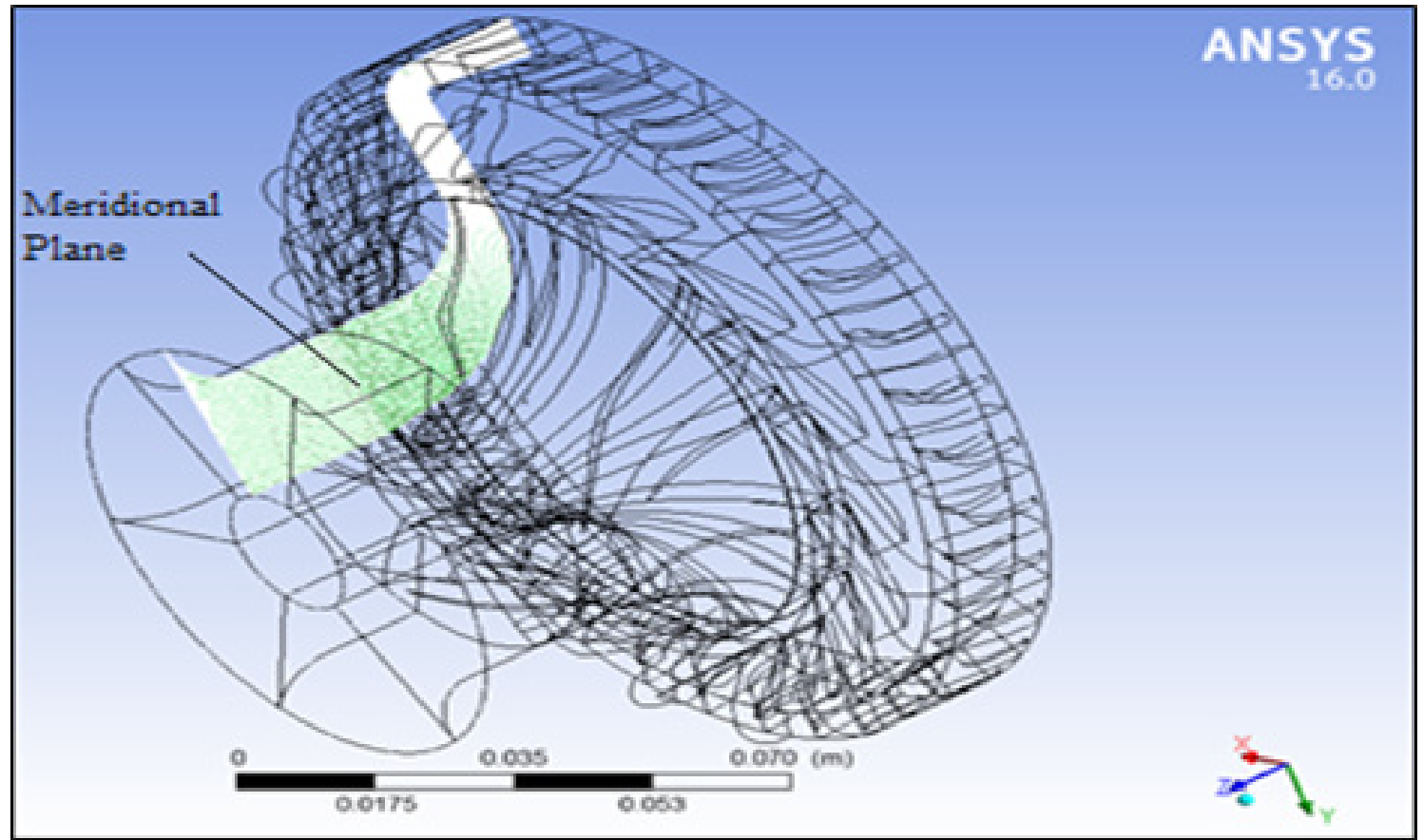

Fig. 10: JetCat's compressor flow path

\subsection{CFD Results}

In this work, six calculations have been made for each number of revolutions: The first one at the design speed point, four in the left part of the performance curve and the last one is in the right part. For each of these calculations, the same mesh generated by ANSYS TurboGrid and
ANSYS-ICEM CFD mesh is used.

For each calculation, a steady state simulation is used at the beginning to predict the performance of the compressor which gives values of $\dot{m}$ far from the surge point. The stream lines of the flow passing through the compressor can be seen in figure 11 .

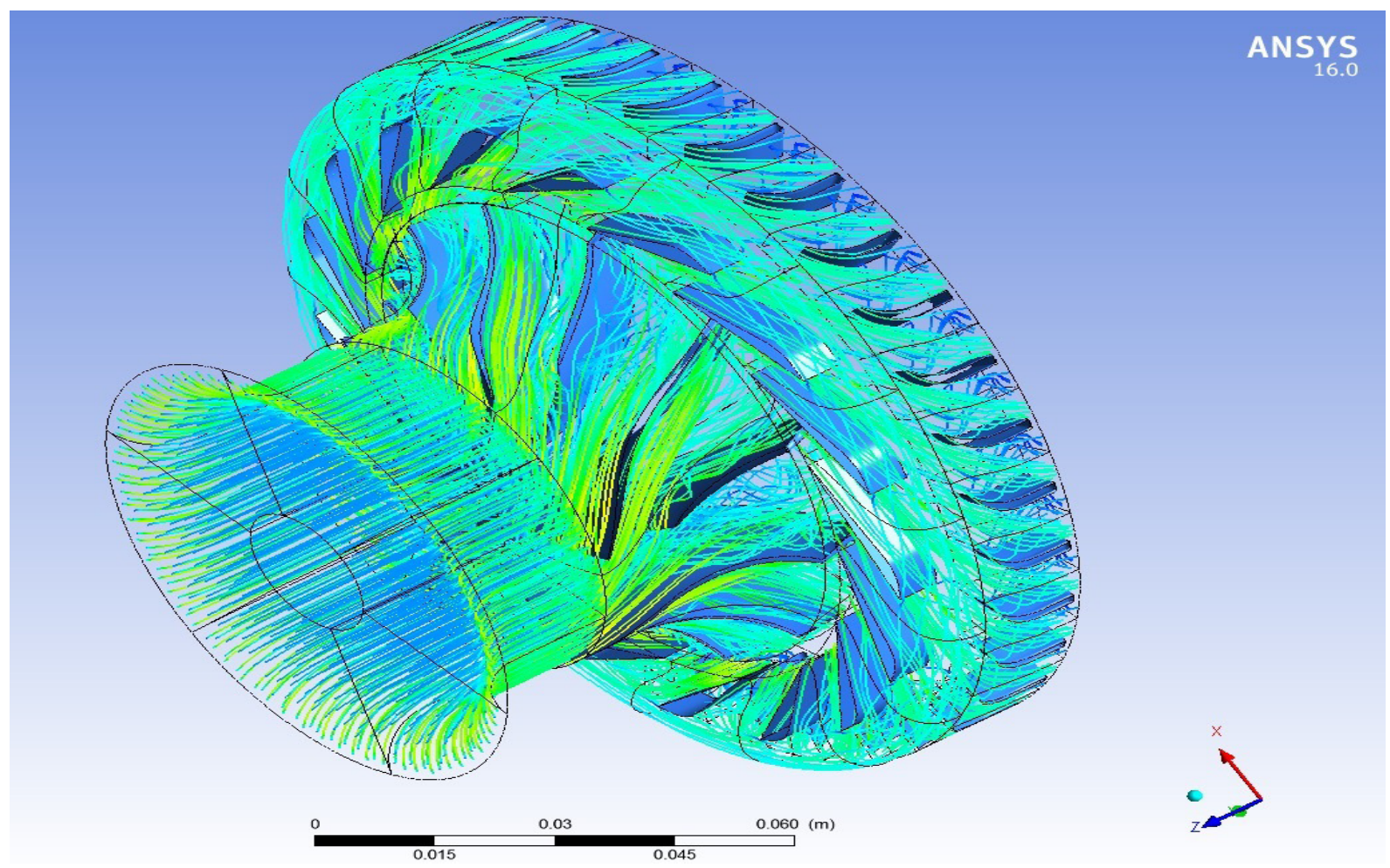

Fig. 11: Streamlines in JetCat's Compressor 
As $\dot{m}$ decreases towards the surge point, the steady state simulation fails to give stable results and the $\dot{m}$ monitor shows the tendency of the solver to go towards zero mass flow. Figure 12 shows the complete failure of the solution when reaching zero flow, ( $\dot{m}=0$ ), using steady state simulation near the surge point. At this state, a transient simulation is selected and the solver succeeds to reach the surge point.

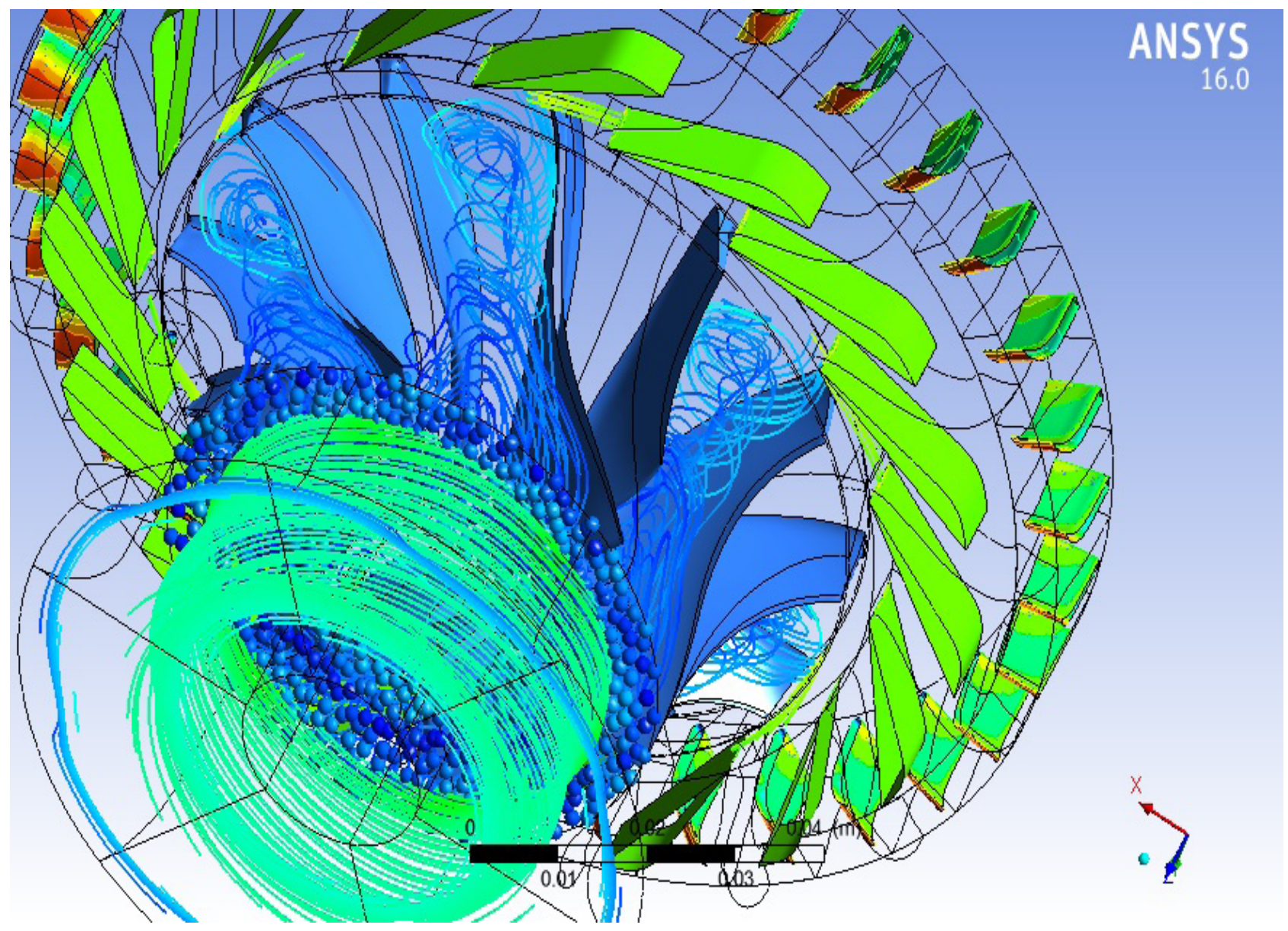

Fig. 12: JetCat's Compressor surge

The used procedure to reach the surge point at each relative speed is illustrated in figure 13. Where the variation of $\dot{m}$ at the compressor outlet (for one passage of the total 34 guide vane passages of the vanned diffuser) with accumulated time step at off-design case of compressor operation at $90 \%$ of the design point rotational speed is shown as an example.

For each of the considered rotational speeds a steady state simulation is selected with an assumed value of the compressor output static pressure then after the run ends, CFX results are obtained. With the same rotational speed, a higher value of the compressor output static pressure than the first run is chosen and a steady state simulation is again selected where new CFX results are obtained. This procedure is continued until reaching the point at which the program fails to solve the state. At this point a transient simulation is selected with initial values resulted of the last successful steady state run. After a short time of running the transient simulation the mass flow rate at the outlet of the compressor starts to fluctuate and a noticeable loss in mass flow rate atthe outlet is noticed. After a short time, a peak is formed and this point is considered as the surge point, Figure 13. 


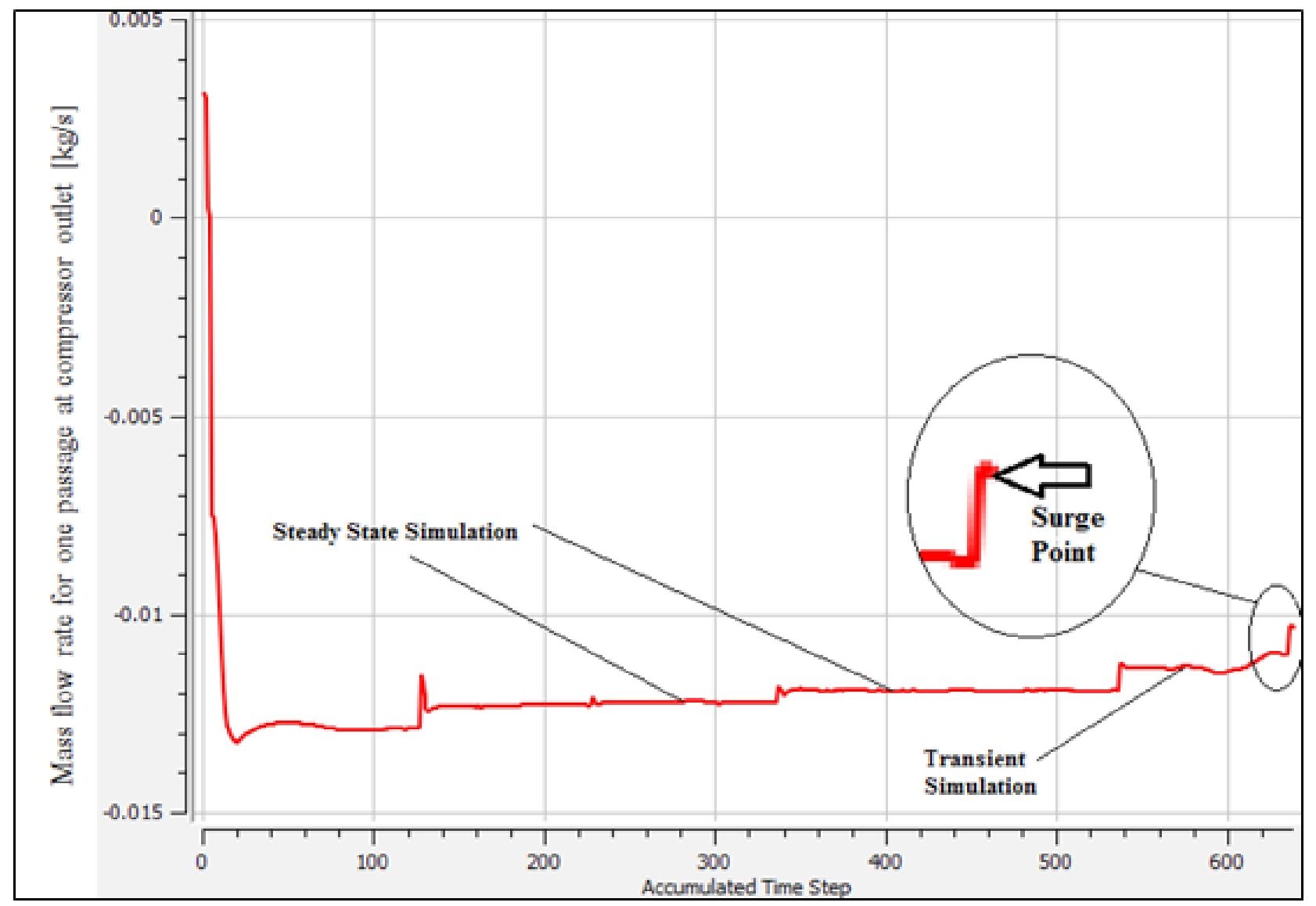

Fig. 13: P-Mass Boundary Flow Compressor outlet at $100800 \mathrm{rpm}(\bar{n}=0.9)$

A velocity vector field is created on a plane near to the impeller shroud close to the surge point at $90 \%$ of the design rotational speed. A recirculation existence of a vortex on this plane is observed as shown in figure 14 .
Some of the vectors are directed towards the impeller inlet as seen on the zoom part of the figure. It can be supposed that this recirculation occurrence is the symptoms of surge onset.

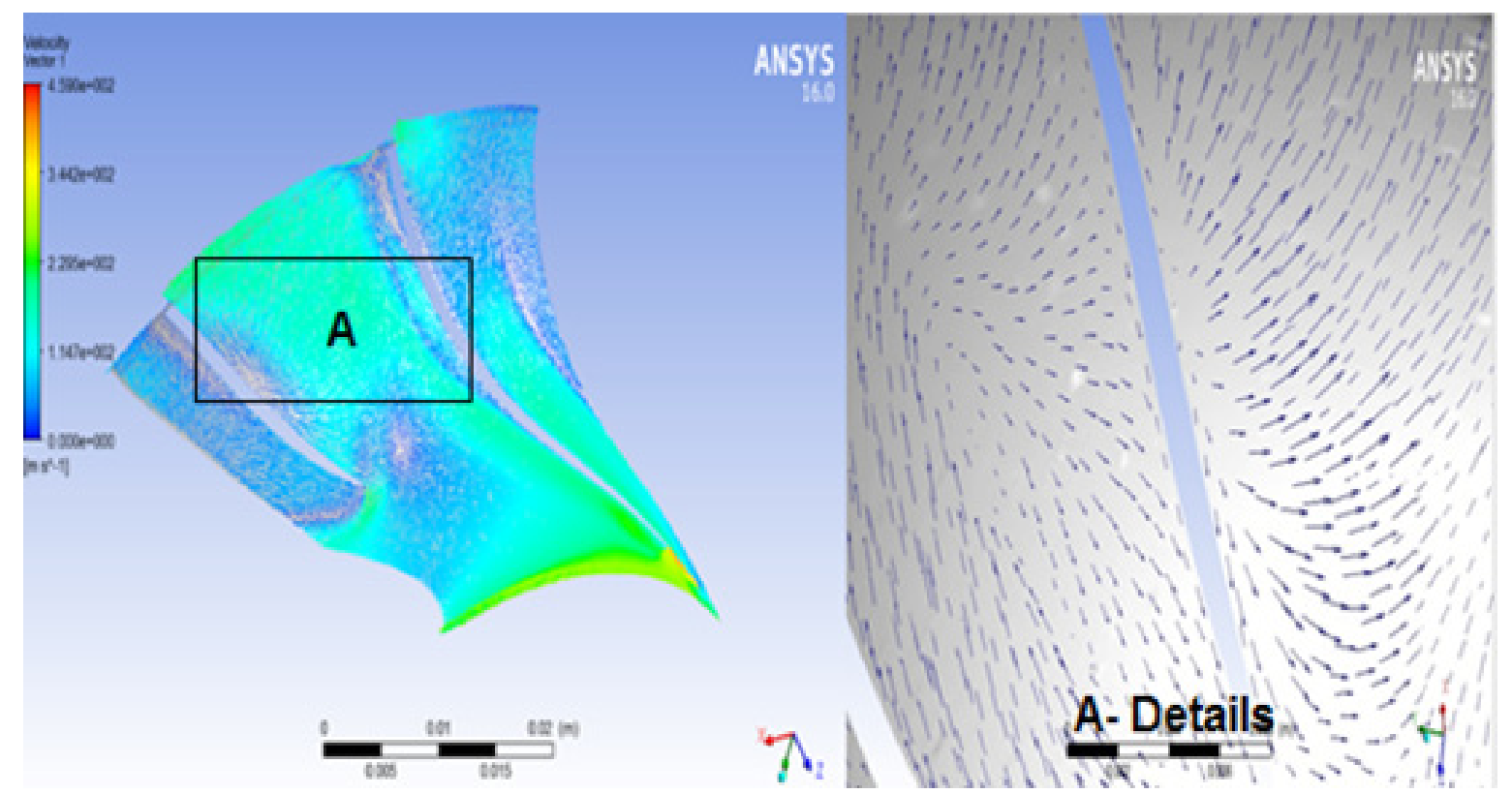

Fig. 14: Recirculation area at surge point 
Using the same procedure at each rotational speed, the JetCat P200-sx Compressor map of pressure ratio and compressor total adiabatic efficiency vs. corrected $\dot{m}$ is represented in figures 15 .

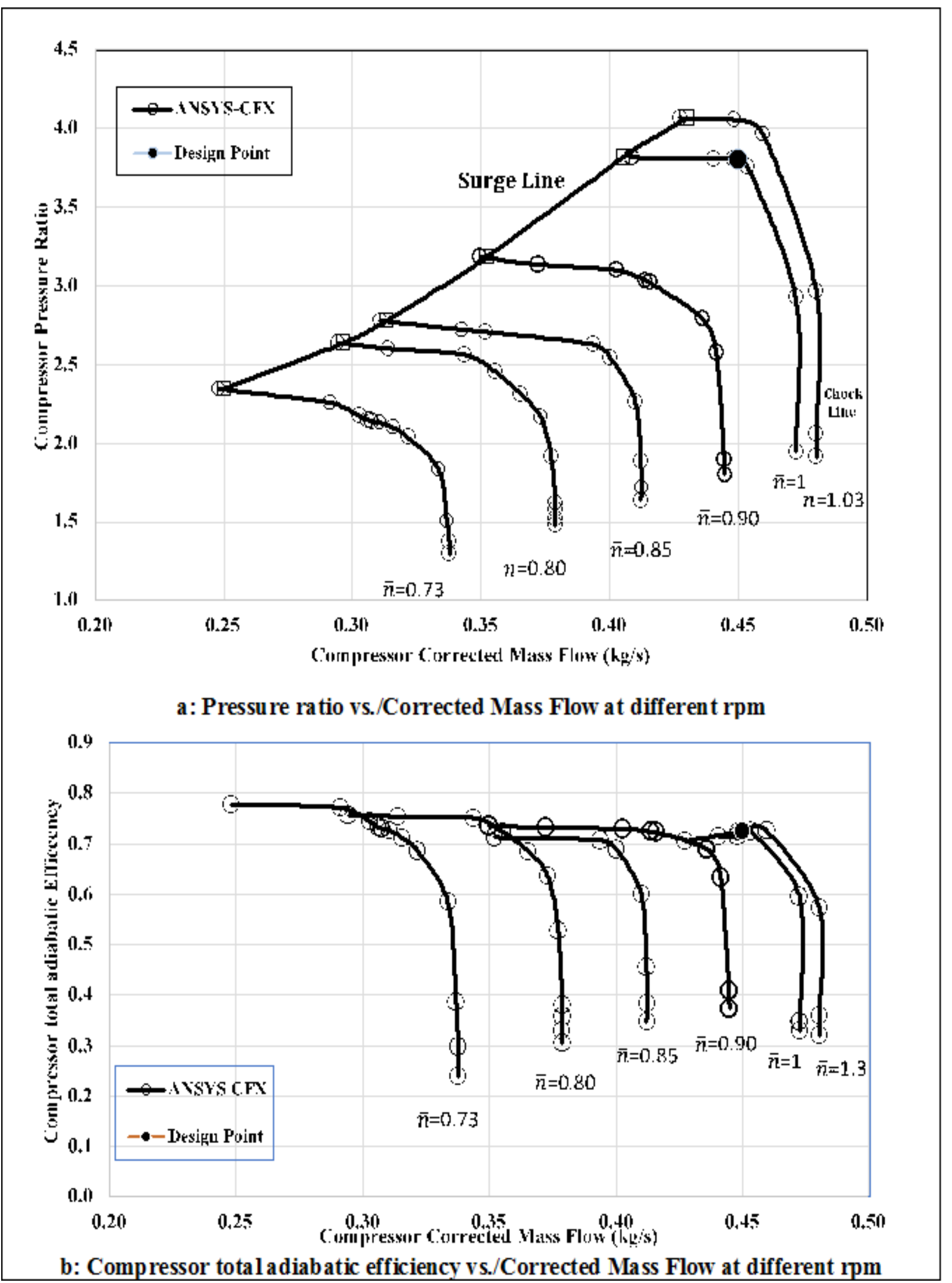

Fig. 15: Compressor performance map using CFX 
V. Approximate Method

An approximate method written in MATLAB elaborated, verified and published ${ }^{[13]}$ is used to calculate the variation in both compression ratio and compressor total adiabatic efficiency with $m$ at design speed and at different rotational speeds. As result, the whole performance compressor map generated is shown in figures 16 .



Fig. 16: Compressor performance map using approximate method

VI. Results and discussion

The purpose of this section is to present the results obtained from CFD and MATLAB, compare and analyze shared and different points. Figure 17 shows the pressure ratio characteristics obtained from both the CFD and the MATLAB calculations for all compressor rotational speeds. 


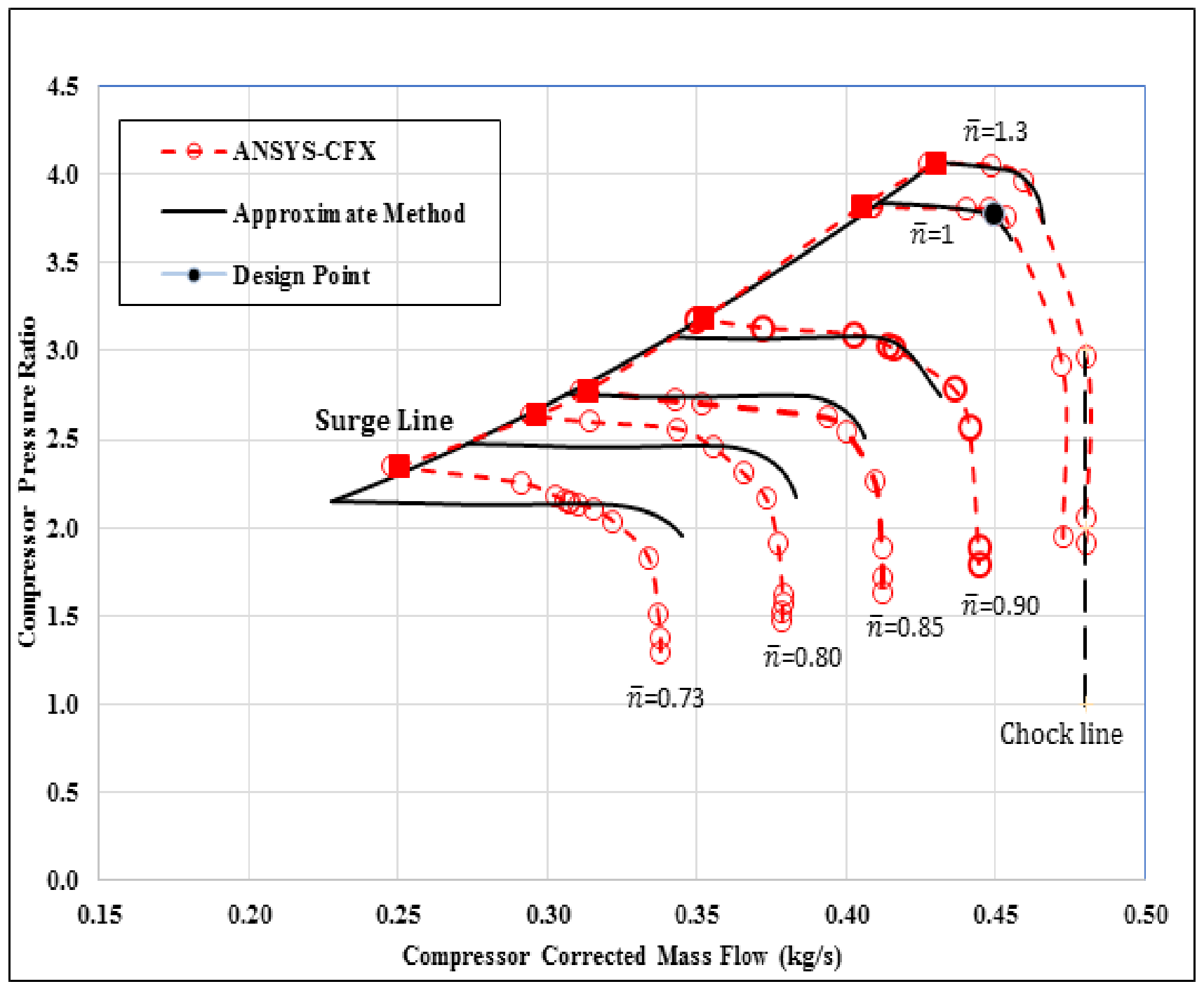

Fig. 17: Comparison of pressure ratio vs./corrected mass flow at different rpm

It is noticed that differences between CFD and MATLAB results are changeable with the impeller rotational speeds. In fact, at design speed and at $\bar{n}=1.03$ of the designed rotational speed it can be seen that both CFD and approximate method results are closely to be identical while with lowering the rotational speed the gaps between CFD and MATLAB increase which is commonly expected because the data used in approximate method is predicted for the large-scale gas turbine engine radial compressors. Also, both estimated surge lines have a good agreement and are close to each other. 


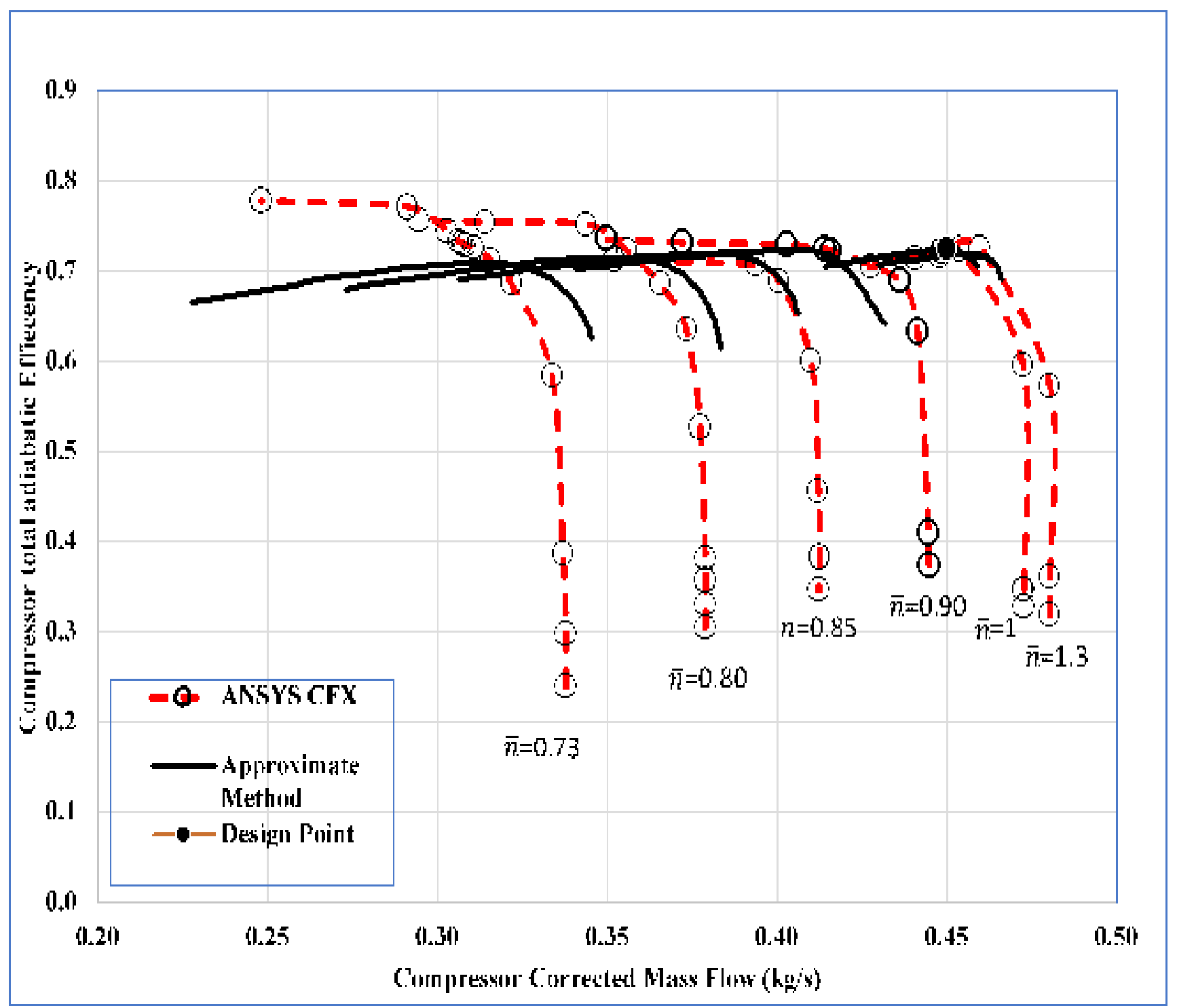

Fig. 18: Comparison of the compressor total adiabatic efficiency vs./corrected mass flow

Figure 18 shows the relation between compressor total adiabatic efficiency and mass flow rate for the same rotational speeds values. Compressor efficiency curves calculated by CFD and approximate method have the same trend as mentioned for the compressor pressure ratio curves.

MATLAB lines are steeper than curves generated by CFD with $\dot{m}$ decrease after reaching maximum efficiencies, CFD efficiency values are higher than the predicted values by MATLAB due to the assumed constant losses values.

Such deviation between the approximate and CFD simulation coincides with published results of similar researches on turbomachinery ${ }^{[13,15]}$ where deviation reached up to $8 \%$ at minimum revolution speed.

\section{Conclusion}

This work demonstrates the usage of CFD simulations to model numerically the flow field through a centrifugal compressor and consequently determining its performance map. Also, the paper explains a possible way for predicting the surge point using CFX solution monitoring with both steady state and transient simulations to evaluate surge onset.

Using the approximate method for prediction the JetCat P200-sx compressor map shows how multiple plot 2-D graphs used in different references can be digitized, interpolated and used in an automated computation. This technique can be used for many other GTE's compressors off-design calculations.

By comparing both results it can be said that prediction of a centrifugal compressor performance using approximate method with MATLAB gives good results when compared with CFD, which makes approximate analytical method preferable, more flexible and easier to use in the compressor early design phase and much more economic from point of view of both time and cost. 


\section{References}

[1] Elzahaby, A. M., Ghenaiet, A., and Elfeki, S. "Theoretical Prediction of Radial Flow Compressor Surge Line," Modeling, Measurement and Control, C, AMSE Press Vol. 41, No.3, 1994, pp. 53-63

[2] Elzahaby, A. M. Theory of jet engines, Printed lectures: Military technical college, MTC, Egypt, 2013.

[3] Boyce, P.M., " Centrifugal Compressors: A Basic Guide," Oklahoma, USA, PenWell Corporation, 2003

[4] ArdaCeylanoglu, "An Accelerated Aerodynamic Optimization Approach for a Small Turbojet Engine Centrifugal Compressor," Master thesis, The Graduate School of Natural and Applied Sciences of Middle East Technical University, Turkey, 2009.

[5] "JetCAT USA," http://www.jetcatusa.com/

[6] Davison, C. R., and Birk, A. M. "Steady State and Transient Modeling of a Micro-Turbine with Comparison to Operating Engine," ASME Turbo Expo 2004: Power for Land, Sea, and Air. Vol. 6, Vienna, Austria, 2004. [7] Leylek, Z., Anderson, W. S., Rowlinson, G., and Smith, N. "An Investigation in to Performance Modeling of a Small Gas Turbine Engine," Proceedings of ASME Turbo Expo 2013: Turbine Technical Conference and Exposition. San Antonio, Texas, USA, 2013.

[8] Mehrdad, P., Nathan, F., James, P., Eric, F., and Alireza, B. "Dynamic Modeling of a Turboshaft Engine Driving a Variable Pitch Propeller: A Decentralized Approach," 47th AIAA/ASME/SAE/ASEE Joint
Propulsion Conference and Exhibit. American Institute of Aeronautics and Astronautics, 2011. 14

[9] T.V. Trebunskikh, A.V. Ivanov, G.E. Dumnov," FloEFD simulation of micro-turbine engine," Mentor Graphics, Moscow, Russia, 2011.

[10] MingYao Ding, Clinton Groth, Suresh Kacker, and Douglas Roberts." CFD Analysis of Off-design Centrifugal Compressor Operation and Performance", University of Toronto Institute for Aerospace Studies, Canada, 2006.

[11] ANSYS-CFX Solver Theory Guide, ANSYS Inc., 2016.

[12] Perez J., Chiva S., Segala W, Morales R.” Performance Analysis of Flow in an Impeller-Diffuser Centrifugal Pumps using CFD”, Dep. Mechanical Engineering and Construction, Jaume I University of Castellón, Castellón, Sapin, 2010.

[13] Elzahaby, Mohamed K. Khalil, Hesham E. Khalil, "Theoretical and Experimental Analysis of a Micro Turbojet Engine's Performance", International Journal of Scientific and Engineering Research, Volume 7, Issue 1, January 2016.

[14] Bosman Botha van der Merwe, "Design of a Centrifugal Compressor Impeller for Micro Gas Turbine Application", Faculty of Mechanical and Mechatronic Engineering at Stellenbosch University, December 2012.

[15] Nader Abdelhameed Mahmoud
"Investigation on the Improvement of the performance "Investigation on the Improvement of the performance
of Small Turbojet Engines", Military Technical College, December 2017. 
NOMENCLATURE

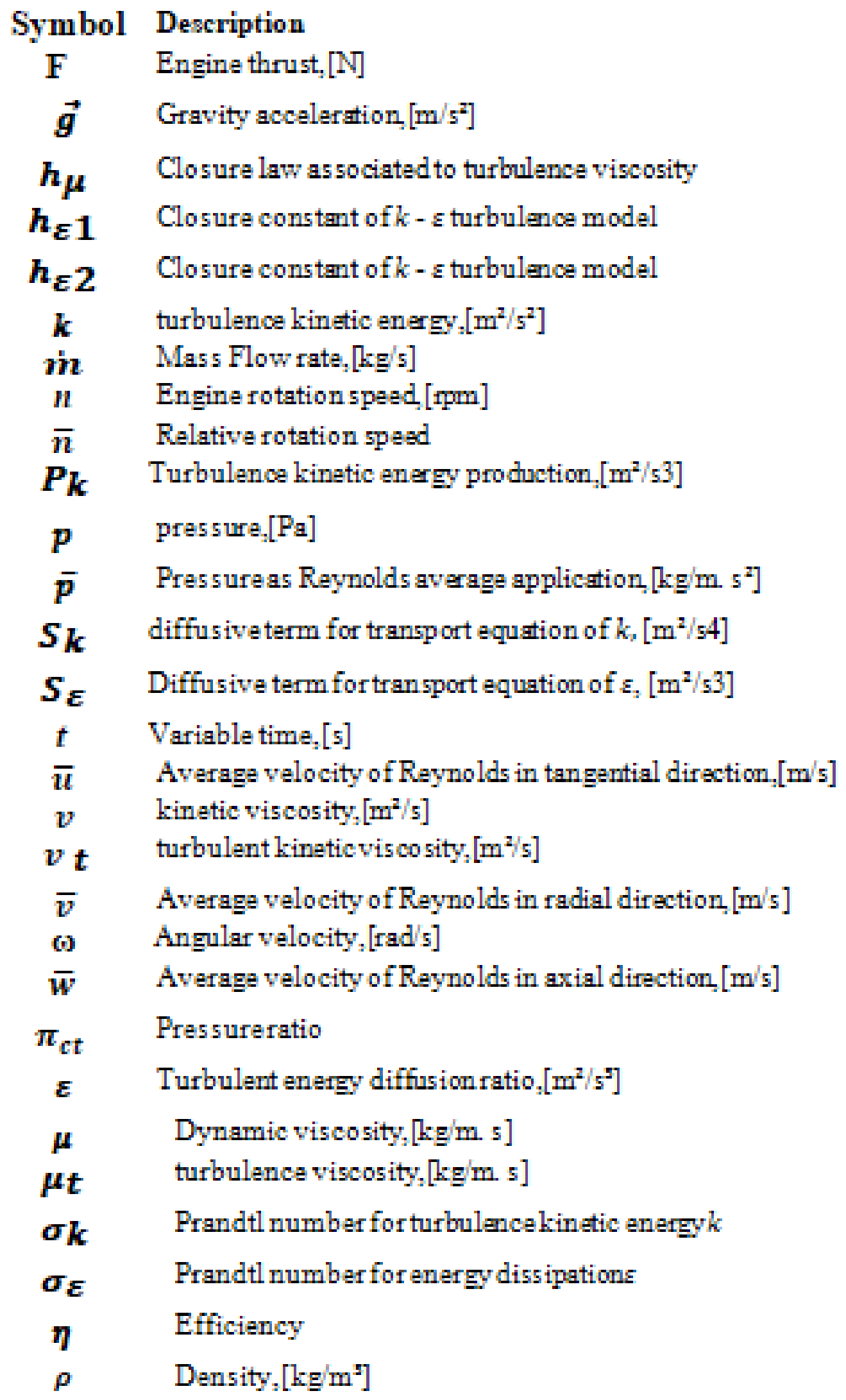




\section{SUBSCRIPT}

$\begin{array}{cl}\text { ANSYS } & \text { Analysis System } \\ \text { CFD } & \text { Air } \\ \text { computational fluid dynamics } \\ c & \text { Coordinate Measuring Machine } \\ \text { DNS } & \text { Direct numerical simulation } \\ \text { EGT } & \text { Exhaust Gas Temperature } \\ \text { GGI } & \text { General grid interface } \\ \text { GIL } & \text { Grid independence limit } \\ \text { GTE } & \text { gas turbine engine } \\ \text { ICEM } & \text { Integrated computer engineering and manufacturing } \\ \text { LES } & \text { Large Eddy Simulation } \\ \text { RANS } & \text { Reynolds Averaged Navier-Stokes } \\ \text { TJE } & \text { Turbojet Engine } \\ t & \text { Total or Stagnation Value } \\ \text { UAV } & \text { unmanned aerial vehicle }\end{array}$

